\title{
Understanding the Allied Health Professions Student Experience of Practice Placements during the First Wave of the Coronavirus Pandemic
}

\author{
*Julie Marchant ${ }^{a}$ \\ a: Guy's and St Thomas' NHS Foundation Trust, United Kingdom
}

\begin{abstract}
In England, a national lockdown came into effect on 23 March 2020 in response to the rapid spread of the Coronavirus. Healthcare services were quickly redesigned or scaled back to meet the significant and rising demands. Many practice placements were discontinued, which resulted in large numbers of Allied Health Professions (AHPs) pre-registration students requiring placements to meet the required practice hours. The challenge for placement providers, who were experiencing increased demand and uncertainty, was to continue providing quality placements. At the local trust, 58 AHP students had a placement between April and July 2020. Some clinical areas offered traditional placements. However due to social distancing rules many placements utilised blended practice; using aspects of both direct face-to-face and remote practice. It is important to understand the student experience in anticipation of future surges of Coronavirus. In total, 36 students responded to a placement survey. Results showed the majority of the students reported positive placement experiences overall. Despite the ever-changing placement landscape and the need for flexibility, it is important to ensure that placements are well planned and that students are well informed about the safety measures in place. It is vital that student's feel welcomed and valued in order to learn and reach their full potential whilst on placement. The use of a blended placement model provided valuable learning experiences, however consideration needs to be given to ensure that students feel part of the team and have confidence that their learning needs are met.
\end{abstract}

Keywords: Allied Health Professionals; COVID-19; NHS; placement; student experience; virtual

\section{Background}

In March 2020, during the first wave of the coronavirus pandemic, health and social care services in the United Kingdom needed to be rapidly redesigned in response to the accelerating numbers of patients with COVID-19 and to ensure the most vulnerable were protected, including those within the healthcare workforce. In a large integrated NHS Trust in South East London, many services were scaled back to

*Corresponding Author: Julie Marchant, Guy's and St Thomas' NHS Foundation Trust, Westminster Bridge Road, London, SE1 7EH United Kingdom.

Email: julie.marchant@gstt.nhs.uk

Journal URL: https://publications.coventry.ac.uk/index.php/pblh

Marchant, J. (2021). Understanding the allied health professions student experience of practice placements during the first wave of the coronavirus pandemic. International Journal of Practice-based Learning in Health and Social Care, Care, 9(2), 39-48, DOI 10.18552/ijpblhsc.v9i2.741

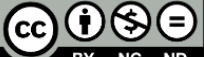

BY NC ND (C) 2021 Julie Marchant. This Open Access article is distributed under the terms of the Creative Commons Attribution Attribution-Non-Commercial No Derivatives 4.0 International License (https://creativecommons.org/licenses/by-nc-nd/4.0/ ), which permits unrestricted non-commercial use, distribution, and reproduction in any medium, provided the original work is properly cited and is unaltered. 
release capacity for treating COVID-19 positive patients. This included increasing the discharge of some patients, postponing or pausing non-essential services and deploying staff across the Trust into areas with the greatest need. There was an accelerated use of virtual consultations (via telephone / video call) as an alternative to face-to-face consultations (Gilbert et al., 2020), owing to social distancing requirements. Staff identified as vulnerable needed to work in different ways, such as via remote working or supporting in areas with low risk. The impact on the clinical workforce was significant and challenged levels of staff resilience (Greenburg, 2020; Spoorthy et al., 2020).

Response to COVID-19 also impacted on the Allied Health Professions (AHPs) placement provision, with many placements discontinued. Placements provide experiential learning that enables the application of taught knowledge to be applied and developed within the practice setting. AHP students complete a minimum of 1,000 hours of practice as part of the pre-registration requirement (Health Education England [HEE], 2020). Reports suggest that placements decreased nationally by $40 \%$ as a consequence of COVID-19 (Taylor, 2020a). This resulted in large numbers of AHP students not able to achieve their required practice hours. At the local Trust, placements for both Physiotherapy and Occupational Therapy fell by $32 \%$ compared to the previous academic year. This resulted in large numbers of AHP students not able to achieve their required practice hours.

To protect students whilst they learn during the pandemic, NHS England introduced employment contracts for students on placement, which provided employment protection inclusive of death in service (Health \& Care Professions Council [HCPC], 2020a; HEE, 2020). Alternatively, providers could offer a work opportunity to support frontline services, which enabled students to be employed as support workers whilst being supported to achieve their required practice hours.

NHS placement providers experiencing increased demand and uncertainty were challenged to continue to provide quality placements, ensure students were supported to meet the standards of proficiency, and maintain the flow of students into the AHP workforce ( $\underline{\mathrm{HCPC}, 2020 \mathrm{~b}})$. At the local Trust, all AHP students had paid placements between 1 April and 31 July 2020. Whilst some clinical areas offered traditional placements (direct face-to-face placements), there was a greater variety of placement models during this period, including research placements, rotational placements and hybrid placements (combination of placement models). Many placements utilised some form of remote (virtual) practice, both as a response to COVID-19 and to reflect changing practices in healthcare.

There is limited literature on the perceptions of AHP students on placement during COVID-19. It is important to understand the student experience, particularly in anticipation of future surges. Furthermore, given that many placements involved remote practice, it is vital to understand the impact of this innovation on practice learning to continue to develop sustainable placement models and comprehensively develop our future AHP workforce. This project aimed to understand the AHP student experience during the initial surge of COVID-19 across six areas: pre-placement support, induction to the placement, safety and well-being, placement support, remote practice, and the learning experience.

\section{Methods}

Ethics approval was not required for this study (NHS Research Ethics Committee). Research approval was sought and gained by a member of the Trust Quality Improvement and Clinical Audit Committee, on 6 August 2020. All participants were informed that any involvement in the project was voluntary and informed consent was given. Eligible participants were 58 AHP students on placement between 1 April and 31 July 2020. Survey methodology was utilised to collect comparative data across participating students. A purposive sample of eligible students were invited to participate by email, which contained a link to an online survey. Each participant was allocated a unique survey number, which ensured anonymity throughout the data collection process. The survey contained a total of 26 questions. Six pertained to demographic information. The remaining questions focused on the six areas of interest regarding the placement experience; 17 questions included non-compulsory, non-directive feedback questions to elicit open-ended comments, which provided additional insights to the question responses (Decorte, 2019). The remaining three questions were open questions. Using framework analysis, comments were categorised into the primary areas of the study, analysed and coded to determine subthemes using a constant comparative method (Gale et al., 2013). Comments and sub-themes were used for 
data extraction and interpretation. Comments are used in the findings to reflect the original accounts of the participants.

\section{Findings}

A total of 36 AHP students participated in the study, a participation rate of $62 \%$; 19 physiotherapists (53\%), seven Speech and Language Therapists (19\%), five Occupational Therapists (14\%), four Therapeutic Radiographers (11\%), and one Diagnostic Radiographer (3\%).

A coding frame of 17 sub-themes was determined from the narrative responses (Figure 1).

\section{Figure 1}

Coding framework

\section{Categories}

\begin{tabular}{ll}
\hline Comments related to pre-placement support & Placement Information \\
\hline Comments related to induction to placement & Welcome \\
& Communication \\
Comments related to safety and well-being & Training \\
\hline & Safety Information \\
Comments related to placement support & Educator support \\
& Feeling part of the team \\
Comments related to remote practice & Supervision and Learning \\
\hline Comments related to the learning experience & Access to IT infrastructure \\
& Structure of model \\
& Inclusivity \\
\hline
\end{tabular}

\section{Pre-Placement Support}

All AHP students received information about the placement and AHP clinical induction prior to the placement (Figure 2). As part of pre-placement support, 97\% of students were contacted, welcomed to their placement and informed about Trust Corporate induction, which supported student transition into the clinical setting. This was indicated in one quote: "We received information before this placement, so we were already aware of what we [would] do during this placement".

The majority of students $(89 \%)$ indicated they received information about their local induction prior to their placement. Four students (12\%) indicated they did not receive information about local induction. Of these, two were already employed within the department on the staff bank and did not require an induction, and one had already been inducted to the department when they first started the placement, prior to COVID-19. 
Figure 2

\section{Survey findings}

\begin{tabular}{|c|c|}
\hline Six areas of placement provision & $\%$ respondents \\
\hline \multicolumn{2}{|l|}{ Pre-Placement Support } \\
\hline I received a welcome letter/email/ call from placement setting & $97 \%$ \\
\hline I received information about Trust Corporate Induction & $97 \%$ \\
\hline I received information about AHP clinical eLearning & $100 \%$ \\
\hline I received information about local induction & $89 \%$ \\
\hline I received information about the placement & $100 \%$ \\
\hline \multicolumn{2}{|l|}{ Induction to paid placement } \\
\hline Trust Corporate Induction was useful & $50 \%$ \\
\hline AHP Clinical Induction eLearning modules were useful & $67 \%$ \\
\hline Local Induction was completed in the first week & $92 \%$ \\
\hline Local Induction was useful & $86 \%$ \\
\hline \multicolumn{2}{|l|}{ Safety and Well-being } \\
\hline I received information about COVID and safe ways to practice in my clinical area & $94 \%$ \\
\hline I felt safe on my placement & $100 \%$ \\
\hline \multicolumn{2}{|l|}{ Placement Support } \\
\hline I was satisfied with the supervision I received on placement & $100 \%$ \\
\hline I felt part of the team & $89 \%$ \\
\hline \multicolumn{2}{|l|}{ Remote (virtual) learning* } \\
\hline I was satisfied with support I received & $81 \%$ \\
\hline The IT structures enabled me to complete the placement successfully & $77 \%$ \\
\hline I had access to the necessary clinical health records & $64 \%$ \\
\hline My learning needs were met & $64 \%$ \\
\hline Remote learning did not affect the quality of supervision and support I received & $77 \%$ \\
\hline I felt part of the team & $57 \%$ \\
\hline \multicolumn{2}{|l|}{ The Placement Experience } \\
\hline I had a positive placement experience & $94 \%$ \\
\hline
\end{tabular}

\section{Induction to paid placements}

Previously, students were not required to complete Trust corporate and AHP clinical induction programmes. Due to the need for an employment contract, all participants were required to complete both.

Half of the students found Trust corporate induction useful. Student comments indicated that some did not understand the relevance of information to their placement and others felt this information was more relevant to those on longer placements, including "I think this would have been more useful, had I been on a longer placement. As it was, it felt like a long process without much relevance to the specific placement".

All respondents completed local induction within the first week of the placement. The majority of student's (86\%) felt that their AHP local induction was useful and $14 \%$ were undecided. Students indicated they felt welcomed into the placement:

All of the team have been very welcoming and supportive. I feel the pace of my induction was done very well, I was not overloaded with too much information at any point and every member of the team has been happy to answer questions and support my learning.

The majority of respondents (67\%) perceived the AHP Clinical Induction eLearning modules as a useful part of their training programme, whereas $17 \%$ were undecided and $17 \%$ felt that AHP clinical induction was not useful. Student comments indicated that there was some confusion as to which training module 
was relevant for them, including "It was confusing trying to figure out specifically what training I was required to do".

\section{Safety and well-being}

The majority of respondents (94\%) indicated they received information about COVID-19 and safe ways to practice as part of local induction and all students reported they felt safe on their placement in relation to COVID-19 and the associated risks. Comments showed that information on well-being and safety equipment were important to how safe students felt on placement. One student mentioned the following: "All of the COVID related information was communicated across the eLearning modules - this was really helpful. I received enough PPE throughout my placement”.

\section{Placement Support}

Student comments indicated that they felt well supported on placement by their educators. This theme was shown to be a key aspect in students reporting a positive placement experience, including these two quotes, "They were extremely supportive", "The team and support from practice educators - Given the situation and working from home, the team still efficiently managed appointments and I was very grateful to be offered a placement within the trust".

In total, $89 \%$ of respondents indicated that they felt part of the team:

I attended group huddles and was encouraged to be involved in these and contribute. I also sat in the sessions of other therapists and ran groups with other members of the team. I felt welcomed and valued by the team.

Some students $(11 \%)$ were undecided and no respondents indicated that they did not feel part of the team.

The team and our practice educators were highly welcoming and encouraging to participate with the team and contribute towards MDT discussions. This was the first adult placement we had...I felt we both needed to spend a lot of solo time together to plan therapy goals and sessions, which impacted how we could connect with the team. The workload became a little more manageable towards the end of the placement, where we began to feel like we could spend more time being present with the team.

All respondents felt satisfied with the supervision they received on placement. One student indicated that "Despite all of the changes and uncertainty due to COVID, the staff at my placement setting...really went above and beyond to facilitate my learning and provide support. They were amazing!"

\section{Remote Practice}

A blended learning model, with aspects of both face-to-face practice and remote practice, was accessed by 14 students in total. Of those receiving a blended placement, $77 \%$ felt that the IT structures enabled them to complete the placement successfully, stating "The IT department were very helpful in setting up my remote access". Many students commented that whilst they felt the IT structures were accessible, setting up the systems took time and were not without technical glitches:

I did eventually manage to access all the IT systems, but it took a lot of time and effort to do so and there seemed to be a number of issues setting up my accounts in particular, where my peers did not always have the same issues.

The majority of respondents indicated they had access to the necessary clinical notes (64\%); however, comments showed that there were challenges in accessing records:

Due to being provided with an incorrect email address, I could not access clinical notes remotely. After ringing IT who very helpfully enabled CareNotes access for me, I still couldn't login...Unfortunately I was not able to remotely access CareNotes throughout the entirety of my placement 
In terms of the placement model and structure, $81 \%$ of respondents were satisfied with the blend of direct and remote support. Feedback included "I was surprised how well the model worked, though missed having face to face supervision and some of the tasks were definitely harder to do remotely, particularly working with children", and "I was lucky and mainly work[ed] clinically, however a full remote placement... would not have been as satisfactory".

However, 64\% of students indicated that remote practice impacted on the quality of their learning. Comments indicated that this may be due to technical issues that interrupted observations, virtual practice and less hands-on learning, including "To some extent, it reduced the time I spent on the job learning...However I still met most of my learning needs", and:

Some of the criteria were definitely harder to hit due to remote working, such as multidisciplinary / joint work, and observations, which were often affected by connection / tech issues. Overall I was able to meet most criteria with some creative interpretation.

Most students felt that remote learning did not affect the quality of their supervision with comments generally positive about supervision, including "I still had lots of opportunities for supervision from my clinical educators and lots of opportunities to reflect on sessions with them".

Students expressed differences of opinion in terms of the impact of the placement in relation to feeling part of the team. Some (57\%) felt that remote practice did not impact on feeling part of the team, with one student stating "I felt very connected to the team and well supported by my [educator]. I was happy doing appointments over video platforms". However, $43 \%$ felt that it did:

Only in terms of the social aspect and getting to know people better. I didn't feel as integrated in not being able to take tea / coffee breaks, casual office chats etc. On the work side of things, everyone was very accommodating and professional and I felt part of the team.

\section{Finance}

An emerging theme from the data was regarding contracting and financial pressures, which resulted in some students feeling confused. One student included:

I did not receive my contract until the final week of my placement, and felt that the communication... between HR and my specific area of work was not very smooth in terms of what the expectations were for payment...I completely appreciate that these are exceptional times and everyone was doing their best!

However, some students indicated that the need for employment contracts benefited them in terms of having less concerns about their financial situations. Feedback from responses included " ... not thinking about finance issue[s] while on placement - as I know income [was] coming in which [meant] I am able to focus on my study more".

\section{Discussion}

The project aimed to understand the AHP student experience during COVID-19, to inform practice in anticipation of future surges. A vital element for the success of any placement is that it is well planned and that students feel supported, safe, and have clear expectations about the placement. Pre-placement support is an important consideration in creating positive learning environments for delivering quality placements (Mulholland et al., 2006). In response to the pandemic, AHP placements were centrally managed, where previously they had been managed uni-professionally. This included consultation with AHP Education Leads to agree and implement standardised processes in welcoming students to the Trust and providing consistent pre-placement information. The placement setting then provided specific information about the placement, including primary client group, working patterns and learning opportunities. Findings demonstrated consistency in pre-placement support. During the current pandemic and increasing uncertainty, it is efficacious to standardise AHP pre-placement support processes to ensure a consistent approach in how students are supported into their placements. In the future, the 
standardisation and central coordination of placement provision will continue to be reviewed and developed by the local Trust.

Induction programmes are an important way to welcome AHP students into the practice setting and are a requirement at the Trust. A positive and student-friendly culture improves the quality of the placement experience (Rodger et al., 2011). Students are more likely to have a positive placement when they have felt welcomed and valued (Hamshire \& Wibberley, 2017). This may improve patient outcomes (Grobecker, 2016), reduce stress, and foster confidence in students (Bradbury-Jones et al., 2011). Placement inductions have an important function in being the first experience the student has of the placement. They should be both welcoming and informative, orientate the student to the department, and outline learning objectives and expectations of the placement. Findings demonstrated that inductions occurred within the first week and comments indicated that students felt welcomed, although some students reported that the relevance of Trust corporate induction to the placement was unclear. Trust corporate induction is designed to welcome and orientate newly appointed employees to the Trust; including both clinical and non-clinical staff. Due to the rapid introduction of employment contracts, new processes for AHP student induction could not be achieved, which may explain the findings. AHP students will not be required to attend Trust corporate induction following the removal of paid placements on 31 July 2020. To supplement corporate and local induction programmes, students completed the AHP clinical induction eLearning programme to support them on placement. These comprised of various modules including working in a clinical area and COVID-19, cardiopulmonary resuscitation (CPR) and the principals of CPR with COVID-19 patients, personal protective equipment, and an introduction for AHPs to the Trust. Due to the rapid nature of the response to COVID-19, AHP students were expected to complete all the modules. Findings showed that the eLearning modules need to be tailored to the practice setting to be meaningful to students.

The impact of the coronavirus pandemic on healthcare services was unprecedented. The subsequent impact on the mental health of healthcare professionals has been the focus of recent studies (Greenburg, 2020; Spoorthy, et al., 2020). Numerous factors have been identified as impacting on mental health including limited resources, threat of exposure to the virus and duty of care, longer shift patterns, disruption to sleep, work-life imbalances, increasing workloads, and lack of sufficient information (Raudenská et al., 2020). Whilst there is currently a paucity of studies exploring the impact of the pandemic on student mental health, it may be reasonably assumed that many of these factors have also impacted on student placement experience. Indeed, placements regardless of the pandemic can be highly stressful for students (Blomberg et al., 2014; Burnard et al., 2007). Stress factors relate to a lack of support, clinical workload, perceived lack of knowledge and the attitudes of clinical staff (Bennion et al., 2020; Timmins et al., 2011). To mitigate concerns about the placement, findings demonstrate that it is important for students to receive sufficient information about being on the placement during the pandemic and to have assurance regarding the safety measures in place. It is important for the local induction programmes to ensure there is a discussion about student learning outcomes and also a clear plan for the placement, which is especially relevant for students experiencing an emerging placement model. This will enable students to feel safe, secure and able to learn (Jonsén et al., 2013). A review of pre-placement support is required to ensure consistent information is provided, including access to new safety initiatives such as vaccination programmes, lateral flow test kits and mental health support.

Another important aspect of placement support is creating a sense of belonging for the learner within the placement setting and clinical team (Bradbury-Jones et al., 2011; Dunbar \& Carter, 2017). Establishing a sense of belonging for the student fosters feelings of student security. When a student feels secure they are more likely to share their anxieties and articulate feelings of stress so that they can be appropriately supported (Dunbar \& Carter, 2017). Creating a sense of belonging may be achieved by welcoming the student into the team, valuing them as a member of the team (Bradbury-Jones et al., 2011), and recognising the contributions that they make. Students in this study indicated they felt welcomed and included in teams. However, more careful consideration is required for those on the blended placements with aspects of remote practice, who indicated a feeling of being disconnected from the clinical team. Placement models that promote peer support in virtual environments, such as the Peer Enhanced ePlacement (PEEP) model, foster feelings of belonging (Taylor, 2020b) and provide a valuable coping mechanism for students (Bíró et al., 2016). The relationship between the learner and educator also contributes to students feeling secure. This relationship is an essential component of a successful placement and positive learning environment (Crombie et al., 2013; Mullholland et al., 2006). Whilst the 
study did not specifically explore the learner - educator relationship, findings indicated that learners felt well supported on placement by their educators.

Placement experience is highly variable and the drive to increase student numbers can result in AHP students feeling that they do not always receive in-depth learning opportunities (HEE, 2018). A quality placement is one in which learning is optimal, individualised to the learner and is shown to be a priority to educators (Kirke et al., 2007; Rodger et al., 2011). The supervisory experience is an essential means by which educators ensure that student learning is prioritised. Findings showed that the majority of learners were satisfied with supervision regardless of placement model. Remote working did have an impact on the learning experience, which may reflect the limited opportunities for hands-on experience and joint sessions within virtual placement models (Twogood et al., 2020).

Virtual placements in the UK are at an embryonic stage and there is a paucity of literature. However, many UK organisations rapidly developed placement models that utilised remote practice during the pandemic. A leader in developing virtual placements was Connect Health, who provided 182 virtual physiotherapy placements from April to August 2020 (Twogood et al., 2020). The initial Connect Health model provided students with the experience of patient care via shadowing virtual clinics, across a broad spectrum of specialities (Twogood et al., 2020). Findings suggest that a key element to the success of this type of placement model is a robust virtual infrastructure (Twogood et al., 2020). At the local Trust students were provided with a Trust network account and access to the Trust's virtual infrastructure, including Microsoft Teams to support supervision and reflection sessions, an email account, access to patient health records, and applications that supported virtual clinics, such as Attend Anywhere and BlueJeans, which supported shadowing opportunities and practice in delivering virtual consultations. Findings demonstrated that whilst students had access to the virtual infrastructure, it is important that students have the time to be familiarised with the organisations IT systems. Technical issues were shown to be a primary limitation of remote practice. As concluded by Twogood et al. (2020), the development of guidance documents and step by step resources to support both students and educators in utilising remote placements would be beneficial. Further research is required to understand virtual and blended learning models on placement experience, both in response to the immediate challenges of the pandemic and as sustainable placement models in providing quality learning experiences beyond COVID-19.

The financial pressures experienced by students is widely acknowledged. Financial worry can impact on mental health and ability to perform (Cassidy et al., 2020). Analysis showed that a small number of students commented that the employment contract and additional income enabled them to focus more on their learning. At the local Trust, the employment infrastructure involves multiple teams including recruitment, finance, contracting and the clinical service. The rapid introduction of employment contracts for students did not allow for significant changes to the recruitment process and findings showed that this left some students feeling confused about the contractual elements of the placement.

\section{Study Limitations}

This was a small-scale qualitative study to explore the impact of the coronavirus pandemic on AHP practice placements during the first wave. Whilst generalisations may not be drawn and comparisons to placements outside of the pandemic established, findings may contribute to the understanding of the impact of the pandemic on AHP placement experience. Findings may also contribute to the continuation of AHP placement provision during COVID-19 and maintain the flow of students into the NHS workforce. The researcher was not directly involved in student assessment, placement delivery or direct support of the practice placements. However, the researcher was a member of the AHP education team and has provided strategic support to placement provision and therefore, there was awareness of the researcher's position to the study to minimise bias throughout.

\section{Conclusion}

This study explored AHP student perspectives of practice based learning during the coronavirus pandemic. In the current study the majority of the students reported positive placement experiences overall. Despite the ever changing placement landscape and the need for flexibility, it is important to 
ensure that placements are well planned and that students are well informed about the safety measures in place. It is vital that student's feel welcomed and valued in order to learn and reach their full potential whilst on placement. In response to social distancing guidelines, many placements utilised a blended (remote and face-to-face) placement model. These models may provide valuable learning experiences, however consideration needs to be given to ensure that students feel part of the team and have confidence that their learning needs are met.

\section{Acknowledgements}

Thank you to all the AHP students that participated in the study, and to all the educators and leads that supported placements during the first surge of the pandemic.

\section{Sources of funding}

No funding was received for this project.

\section{ORCID}

Julie Marchant https://orcid.org/0000-0002-7132-9044

\section{References}

Bennion, J., Symons, T., Shearman, I., Holloway, C., \& Kain, R. (2020). PSS-Study: An exploration of physiotherapy student-perceived stress and the related coping strategies whilst on placement. International Journal of Practice-based Learning in Health and Social Care, 8(2), 68-85. https://doi.org/10.18552/ijpblhsc.v8i2.654

Bíró, É., Veres-Balajti, I., \& Kósa, K. (2016). Social support contributes to resilience among physiotherapy students: A cross sectional survey and focus group study. Physiotherapy, 102(2), 189-195. https://doi.org/10.1016/j.physio.2015.05.002

Blomberg, K., Bisholt, B., Engström, A, K., Ohlsson, U., Johansson, A, S., \& Gustafsson, M. (2014). Swedish nursing students' experience of stress during clinical practice in relation to clinical setting characteristics and the organisation of the clinical education. Journal of Clinical Nursing, 23, 2264-2271. https://doi.org/10.1111/jocn.12506

Bradbury-Jones, C., Sambrook, S., \& Irvine, F. (2011). Empowerment and being valued: A phenomenological study of nursing students' experiences of clinical practice. Nurse Education Today, 31(4), 368-372. https://doi.org/10.1016/j.nedt.2010.07.008

Burnard, P., Binti, H.T., Rahim, H.A., Hayes, D., \& Edwards, D. (2007). A descriptive study of Bruneian student nurses; perception of stress. Nurse Education Today, 27(7), 808-818

Cassidy, E., Norris, M., \& Williams, A. (2020). What does it take to graduate? A qualitative exploration of the perceptions of successful physiotherapy graduates from one university in the UK. Physiotherapy Theory and Practice, 36(2), 316-332. https://doi.org/10.1080/09593985.2018.1485799

Crombie, A., Brindley, J., Harris, D., Marks-Maran, D., \& Morris Thompson, T. (2013). Factors that enhance rates of completion: What makes students stay? Nurse Education Today, 33(11), 12821287. https://doi.org/10.1016/j.nedt.2013.03.020

Decorte, T., Malm, A., Sznitman, S. R., Hakkarainen, P., Barratt, M. J., Potter, G. R., Werse, B., Kamphausen, G., Lenton, S., \& Frank, V. A. (2019). The challenges and benefits of analyzing feedback comments in surveys: Lessons from a cross-national online survey of small-scale cannabis growers. Methodological Innovations, 12(1), 1-16. https://doi.org/10.1177/2059799119825606

Dunbar, H., \& Carter, B. (2017). A sense of belonging: The importance of fostering student nurses' affective bonds. Journal of Child Health Care, 21(4), 367-369. https://doi.org/10.1177/1367493517739977

Gale, N. K., Heath, G., Cameron, E., Rashid, S., \& Redwood, S. (2013). Using the framework method for the analysis of qualitative data in multi-disciplinary health Research. BMC Medical Research Methodology, 13(117). https://doi.org/10.1186/1471-2288-13-117 
Gilbert, A. W., Billany, J. C. T., Adam, R., Martin, L., Tobin, R., Bagdai, S., Galvin, N., Farr, I., Allain, A., Davies, L., \& Bateson, J. (2020). Rapid implementation of virtual clinics due to COVID-19: report and early evaluation of a quality improvement initiative. British Medical Journal Open Quality, 9(2). http://dx.doi.org/10.1136/bmjoq-2020-000985

Greenburg, N. (2020). Managing mental health challenges faced by healthcare workers during COVID-19 pandemic. British Medical Journal, 368. https://doi.org/10.1136/bmj.m1211

Grobecker, P.A. (2016). A sense of belonging and perceived stress among baccalaureate nursing students in clinical placements. Nurse Education Today, 36,178-183. http://dx.doi.org/10.1016/j.nedt.2015.09.015

Hamshire, C., \& Wibberley, C. (2017). Fitting in with the team: Facilitative mentors in physiotherapy student placements. Teaching \& Learning Inquiry, 5(2). http://dx.doi.org/10.20343/teachlearninqu.5.2.7

Health \& Care Professions Council (HCPC). (2020a). Joint statement on how we will support and enable the student allied health professional workforce to respond to the COVID-19. https://www.hcpcuk.org/news-and-events/news/2020/joint-statement-on-how-we-will-support-and-enable-thestudent-allied-health-professional-workforce-to-respond-to-the-covid-19/

Health \& Care Professions Council (HCPC). (2020b). Advice for education providers. https://www.hcpcuk.org/covid-19/advice/advice-for-educationproviders

Health Education England. (2018). Reducing Pre-registration Attrition and Improving Retention Report. https://www.hee.nhs.uk/our-work/reducing-pre-registration-attrition-improving-retention

Health Education England. (2020). Current placement expectations of AHP Regulators and Professional Bodies. https://www.hee.nhs.uk/our-work/allied-health-professions/helping-ensure-essentialsupply-ahps/placement-expansion-innovation/current-placement-expectations-ahp-regulators

Jonsén, E., Melender, H. L., \& Hilli, Y. (2013). Finnish and Swedish nursing students' experiences of their first clinical practice placement - A qualitative study. Nurse Education Today, 33(3), 297-302. https://doi.org/10.1016/j.nedt.2012.06.012

Kirke, P., Layton, N., \& Sim, J. (2007). Informing fieldwork design: Key elements to quality in fieldwork education for undergraduate occupational therapy students. Australian Occupational Therapy Journal, 54(1), S13-S22. https://doi.org/10.1111/j.1440-1630.2007.00696.x

Mullholland, S., Derdall, M., \& Roy, B. (2006). The Student's Perspective on What Makes an Exceptional Practice Placement Educator. British Journal of Occupational Therapy, 69(12), 567-571. https://doi.org/10.1177\%2F030802260606901206

Raudenská, R., Steinerová, V., Javurková, A., Urits, I., Kaye, A, D., Viswanath, O., \& Varrassi, G. (2020). Occupational burnout syndrome and posttraumatic stress among healthcare professionals during the novel coronavirus disease 2019 (COVID-19) pandemic. Best Practice \& Research Clinical Anaesthesiology, 34(3), 553-560 https://doi.org/10.1016/j.bpa.2020.07.008

Rodger, S., Fitzgerald, C., Davila, W., Millar, F., \& Allison, H. (2011). What makes a quality occupational therapy practice placement? Students' and practice educators' perspectives. Australian Occupational Therapy Journal, 58(3), 195-202. https://doi.org/10.1111/j.14401630.2010.00903.x

Spoorthy, M. S., Pratapa, S. K., \& Mahant, S. (2020). Mental health problems faced by healthcare workers due to the COVID-19 pandemic-A review. Asian Journal of Psychiatry, 51. https://doi.org/10.1016/j.ajp.2020.102119

Taylor, L. (2020a). Placements post COVID-19 - time for re-evaluation? https://www.advancehe.ac.uk/news-and-views/placements-post-covid-19-time-re-evaluation

Taylor, L. (2020b). PEEP: A virtual alternative placement. OT News, 28(7), 39-41. https://view.joomag.com/occupational-therapy-news-july-2020/0103641001594290775?short\&

Timmins, F., Corroon, A. M., Byrne, G., \& Mooney, B. (2011). The challenge of contemporary nurse education programmes. Perceived stressors of nursing students: Mental health and related lifestyle issues. Journal of Psychiatric and Mental Health Nursing, 18(9), 758-766. https://doi.org/10.1111/j.1365-2850.2011.01780.x

Twogood, R., Hares, E., Wyatt, M., \& Cuff, A. (2020). Rapid implementation and improvement of a virtual student placement model in response to the COVID-19 pandemic. BMJ Open Quality, 9, e001107. https://doi.org/10.1136/bmjoq-2020-001107 